\title{
Oxidative Stress Changes Induced by Methotrexate on Parotid Gland Structure of Adult Male Albino Rat: Can Vitamin C Ameliorate These Changes?
}

\author{
SAMAA SALAH ABD EL-FATAH, M.D.; DOAA MOHAMMED YOUSEF, M.D. and \\ AMIRA E. AL-SEMEH, M.D.
}

The Department Anatomy and Embryology, Faculty of Medicine, Zagazig University

\begin{abstract}
Background: Methotrexate (MTX) is a cytotoxic chemotherapeutic agent for several malignancies and various inflammatory diseases. Salivary dysfunction is one of MTX mucotoxic effects. Vitamin C (vit. C) scavenges the oxidative molecules and free radicals since it is a potent hydrophilic antioxidant.
\end{abstract}

Aim of Study: Is to throw light on the structural alternation in the rat parotid gland after administration of MTX and the probable antioxidant role of vit. $\mathrm{C}$ on these structure alterations.

Material and Methods: Fifty male albino rats were equally divided into 5 groups; Group I: Rats had received a balanced diet for 9 days; Group II: Rats had received vit. C daily by oral gavage $(500 \mathrm{mg} / \mathrm{kg}$ body weight) dissolved in $5 \mathrm{~cm}$ distilled water for 9 days; Group III (MTX-treated group): Animals had received MTX intraperitoneally as one single dose (20mg/ $\mathrm{kg} \mathrm{B.w}$ ) on the third day of the experiment; Group IV (MTXwithdrawal group): Rats had received MTX intraperitoneally as one single dose $(20 \mathrm{mg} / \mathrm{kg} \mathrm{B}$.w $)$ on the third day of the experiment then left without treatment for another 15 days; Group V (MTX + vit. C-treated group): Rats had received MTX intraperitoneally as one single dose on the third day of the experiment and vit. $\mathrm{C}$ by oral gavage 2 days before and 6 days after MTX administration (at same doses mentioned before). The animals of Group I, II, III and V were anesthetized and scarified after 9 days of experiment, while rats of Group IV were anesthetized and scarified after 18 days of experiment. At the end of experiment, parotid tissues were collected for both light and electron microscopy and biochemical investigations.

Results: MTX caused parotid histopathological and ultrastructural alterations. The MTX-treated group revealed loss of normal architecture of parotid tissue. Some parotid acini were completely degenerated leaving large spaces. Other acini appeared with numerous intracellular vacuoles. The ducts appeared dilated with stagnation of secretion. Collagen fibers, inflammatory cells infiltration, congested blood vessels and hemorrhage in between the acini were also detected. Biochemically, the Malondialdehyde (MDA) level of the MTX- treated group was significantly increased while the Glutathione (GSH)

Correspondence to: Dr. Samaa S. Abd El-Fatah,

The Department Anatomy and Embryology,

Faculty of Medicine, Zagazig University level was significantly reduced in comparison with other groups. The MTX-withdrawal group showed little improvement of biochemical parameters, while structural examination still showed signs of degenerations. However, the MTX + vit. Ctreated group demonstrated some improvement of histological features and biochemical parameters as compared to the MTXtreated group.

Conclusions: Methotrexate produces marked degenerative changes in the parotid structure while vitamin $\mathrm{C}$ has the ability to ameliorate these parotid injuries.

Key Words: Methotrexate - Vit. C-Parotid salivary gland - Histological changes - Oxidative Stress.

\section{Introduction}

AT the beginning of last century, the only used treatment for patients with solid tumors was surgery and this resulted in high mortality. Over the last 40 years, chemotherapy achieved a progressive improvement in survival rates of patients with malignant tumors. Methotrexate (MTX) is a cytotoxic chemotherapeutic drug that used in the treatment of malignant tumors and some autoimmune diseases. MTX has cytotoxic effect on cancer cells. Unfortunately, it is non-selective on diseased cells only but also destroy normal tissues especially that with a high rate of proliferation as actively dividing cells of the intestinal mucosa and the hematopoietic cells in the bone marrow.

One of the commonest chemotherapeutic somato-toxic side-effects is mucositis. Oral mucositis causes oropharyngeal pain, oral infections, dental caries, bacteraemia and sepsis beside taste, swallowing and speech disorders. Thus, it does not only affect patient's nutrition or quality of life during and after treatment but also delays treatment completion and dose reduction [3-Я. Saliva secreted by acini of salivary glands and modulated by their duct cells, has a vital role in maintaining oral tissue 
integrity. It provides lubrication, digestion, enamel preservation, antibacterial, antifungal and antiinflammatory functions by its different components. The major salivary glands secrete $90 \%$ of the daily saliva and their malfunction changes the composition and decreases the amount of saliva leading to dry mouth (xerostomia) which is manifested clinically by oral mucositis. Such malfunction was proven to occur with chemotherapy and aggravated its secondary mucotoxic effects [6].

Many adverse effects have resulted from the usage of chemotherapeutic drugs, so protection against their toxicity is necessary. The systemic oxidative stress is the main mechanism of the MTX-induced toxicity. It affects the antioxidant enzyme defense system by significant reduction in the Glutathione (GSH) levels. MTX also decrease metabolism of nucleic acid. The most significant indicator of membrane lipid peroxidation is the Malondialdehyde (MDA) which is arising from the interaction of Reactive Oxygen Species (ROS) with cellular membranes [7].

Ascorbic acid (Vitamin C) is natural antioxidant agent that presents in plasma, body fluids and cells. Vit. $\mathrm{C}$ is also transported to the cells in an oxidized form as dehydro-ascorbic acid. The glandular tissues have the highest concentration of Vitamin $\mathrm{C}$ while muscles and adipose tissues have the lowest level. Vit. C acts as an ROS scavenger and also plays a role in the oxidative stress pathways as an essential coenzyme. So that, many studies in vivo and in vitro have shown the ability of Vit C. to prevent and attenuate the side effects of chemotherapeutic drugs $[8,9]$

This study aimed to investigate the possible antioxidant role of Vitamin C on MTX-induced oxidative damage to rat parotid salivary gland by histological and biochemical methods.

\section{Material and Methods}

Animals: Fifty adult male albino rats weighing 200-250gm each. Only males were used to exclude the role of hormonal difference. They were obtained from the Animal House of Faculty of Medicine, Zagazig University during 2018. All animals were kept under hygienic conditions. Standard food and tap water were administrated. They were housed in fan ventilated wide polypropylene cages with stainless steel tops and wood shavings for bedding. Temperature was maintained at $23 \pm 2^{\circ} \mathrm{C}$. They were accommodated to the laboratory conditions for 15 days before being experimented. All rats received humane care in compliance with Ethical Committee of Zagazig University and in accordance with the
NIH Guidelines for the Care and Use of Laboratory Animals and were approved by the Institutional Animal Care and Use Committee at Zagazig University (ZU-IACUC), Egypt.

Chemicals: Methotrexate (MTX) $(25 \mathrm{mg} / 1 \mathrm{~mL}$ injectable solution), was purchased from Mylan pharmaceutical company, USA. Vitamin C (Vit.C) was obtained in the form of powder from El-Kahira Company of Pharmaceutical Industries, Zagazig, Egypt.

Kits: The bio-diagnostic kits: For estimation of the Glutathione (GSH) and the Malondialdehyde (MDA) levels were purchased from Diagnostic and Research Reagents (Giza, Egypt).

Experimental design: The rats were divided equally into five groups (ten rats for each) as follow: Group I (Control group): Rats had received a balanced diet for 9 days to measure basic parameters; Group II (Vit. C-treated group): Rats had received Vit. C daily by oral gavage $(500 \mathrm{mg} / \mathrm{kg}$ body weight) dissolved in $5 \mathrm{~cm}$ distilled water [10] for 9 days; Group III (MTX-treated group): Animals had received MTX intraperitoneally as one single dose $(20 \mathrm{mg} / \mathrm{kg}$ body weight $)$ on the third day of the experiment [11]; Group IV (MTX-withdrawal group): Rats had received MTX intraperitoneally as one single dose $(20 \mathrm{mg} / \mathrm{kg}$ body weight $)$ on the third day of the experiment then left without treatment for another 15 days; Group V (MTX + Vit. C-treated group): Rats had received MTX intraperitoneally as one single dose $(20 \mathrm{mg} / \mathrm{kg} \mathrm{B} . \mathrm{w})$ on the third day of the experiment and Vit. $\mathrm{C}$ by oral gavage $500 \mathrm{mg} / \mathrm{kg}$ B.w dissolved in $5 \mathrm{~cm}$ distilled water 2 days before and 6 days after MTX administration. The animals of Group I, II, III and V were anesthetized and scarified after 9 days of experiment, while rats of Group IV were anesthetized and scarified after 18 days of experiment. The animals were anaesthetized by intraperitoneal injection of $75 \mathrm{mg} / \mathrm{kg}$ sodium thiopental [12]. Then, the right and left parotids of each rat were excised carefully. Samples from each group were processed for light and electron microscopic examination. While samples for tissue homogenates were wrapped with aluminium foil and kept frozen at $80^{\circ} \mathrm{C}$ until being used for biochemical studies.

Biochemical investigations: Parotid homogenates of 5 rats from each group were used to measure value of the Glutathione (GSH) and the malondialdehyde (MDA, a lipid peroxidation indicator) at the Clinical Pathology Department, Faculty of Veterinary Medicine, Zagazig University. The MDA level was measured by method described by 
Placer et al., [13]. While GSH was measured by the method of Maral et al., [14].

\section{Histological studies:}

A- Light microscope study:

The left parotids of remaining 5 rats of each group were fixed in $10 \%$ formol saline, kept for $24 \mathrm{~h}$ then processed to paraffin blocks. Six micrometers-thick sections were cut and stained with Hematoxylin and Eosin (H \& E) [15]. Stained slides were then examined by light microscope LEICA DM500 at the Anatomy Department, Faculty of Medicine, Zagazig University, Egypt.

\section{B- Electron microscopic study:}

The right parotids of the remaining 5 animals in each group were cut into small fragments (0.5$\left.1.0 \mathrm{~mm}^{3}\right)$, prefixed in $2.5 \%$ glutaraldehyde for $2 \mathrm{~h}$ then postfixed in $1 \%$ osmium tetroxide in $0.1 \mathrm{M}$ phosphate buffer at $\mathrm{pH} 7.4$ and $4^{\circ} \mathrm{C}$ for $2 \mathrm{~h}$. Dehydration and resin embedding were done to obtain resin blocks at Electron Microscope Unit, Histology and Cell Biology Department, Faculty of Medicine, Zagazig University, Egypt. Semithin (1 m) and ultrathin $(60-90 \mathrm{~nm})$ sections were cut using a Leica ultracut (UCT) (Glienicker, Berlin, Germany) at Electron Microscope Research Unit, Faculty of Medicine, Zagazig University. Semithin sections were stained with toluidine blue $(1 \%)$ and examined by light microscope while, ultrathin ones were stained with uranyl acetate then lead citrate $[\mathbf{1 6 , 1 7 ]}$ Stained grids were investigated by a JEOL electron microscope 1010 at the Regional Centre of Mycology and Biotechnology, Al-Azher University, Cairo, Egypt.

\section{C-Statistical data analysis:}

The biochemical measurements were statistically analyzed using "IBM SPSS statistics 21 " and the data were estimated as mean \pm Standard Deviation (SD). ANOVA (one-way analysis of variance) was used to report the statistical significance difference between different groups ( $p<0.05$ was considered significant) [18]

\section{Results}

\section{A- Biochemical results:}

Lipid peroxidation and antioxidant enzyme activity:

The measured data of the lipid peroxidation and the Glutathione (GSH) in the parotid tissues were summarized in Table (1), (Charts 1,2). MTXtreated rats exhibited increase in lipid peroxidation, evidence by significantly increased the mean values of the MDA level compared to control and Vit. Ctreated groups. Meanwhile, co-administration of
Vit. C with MTX revealed significantly decreased the MDA level compared to MTX-treated group and revealed no significant difference from the control group. However withdrawal of MTX showed significant elevation in the MDA levels compared to the MTX-treated rats but still significantly difference from control group. On contrary, the GSH values revealed a significant reduction in rats treated with MTX compared to control and Vit. C-treated groups. While co-administration of Vit. C with MTX revealed significant increase in the GSH values compared to MTX-treated group with no significant different from the control group. However, the value of the GSH tended to increase in MTX-withdrawal group but still be significant difference from control group.

\section{B- Histopathological results:}

Group I (control group): Normal parotid gland histological structure was detected during investigation of $\mathrm{H} \& \mathrm{E}$ stained sections. The parotid parenchyma was formed of closely packed purely serous acini with ducts which were hardly recognized in-between these acini Fig. (1A).

Parotid ultra-thin sections revealed the predominant typical serous cells. They showed large regular euchromatic nuclei and extensive rough Endoplasmic Reticulum (ER) which was arranged as parallel rows of cisternae. Mitochondria were generally few and randomly distributed in between adjacent ER cisternae and also between secretory granules. Junctional complexes were observed between the two closely adjacent serous cells Fig. (1B).

Group II (Vit. C-treated group): Vitamin Ctreated group exhibited nearly normal histological structure in $\mathrm{H} \& \mathrm{E}$ stained sections and ultra-thin ones Fig. (1C).

Group III (MTX-treated group): The MTXtreated group exhibited disorganization of the parotid tissues. Most of the serous acini had irregular outlines and were widely separated. The cytoplasm of the acinar cells was faintly stained. Marked hemorrhage in between the acinar cells was also noticed. The nuclei were displaced peripherally by variable sized vacuoles and also small pyknotic nuclei were noticed Fig. (2A-C). Prominent increase in the interstitial connective tissue accompanied by a reduction in parenchymal structures was noticed in other acini Fig. (2B). While the ducts showed an extensive dilation in some acini with stagnation of secretion. Preductal cellular infiltration was also observed Fig. (2C).

The parotid ultra-thin sections of the MTXtreated group exhibited variable forms of degener- 
ation in the acinar cells. Some acinar cell had irregular heterochromatic nuclei and marked dilated rough endoplasmic reticulum Fig. (2D). Large numerous electron lucent granules were seen in another acinus Fig. (2E). Multiple collagen fibers appeared in-between acini Fig. (2F).

Group IV (MTX-withdrawal group): In the MTX-withdrawal group, signs of parotid degeneration were still present as numerous vacuolated acinar cells with darkly stained nuclei. Also some vesicular nuclei were observed Fig. (3A). The ducts showed dilatation. Some inflammatory cell infiltration around ducts Fig. (3B) had been seen.

The parotid ultra-thin sections of the MTXwithdrawal group still revealed some acinar cells with irregular heterochromatic nuclei and cystic or irregular dilation of endoplasmic reticulum. Small few electron lucent granules were also demonstrated. Wide separation between acini was also detected Fig. (3C).

Group V (MTX + Vit C-treated group $):$ The MTX + Vit. C-treated group showed some improvement in the parotid tissues. Parotid parenchyma showed closely packed purely serous acini. Some vacuolations were still observed. The ducts still showed dilation Fig. (4A).

The parotid gland ultra-thin sections of the MTX + Vit. C-treated group revealed some acinar cells relatively retaining their normal architecture. Their cytoplasm contained well-developed cisternae of rough endoplasmic reticulum, few mitochondria and numerous small electron-dense secretory granules. The acinar nuclei retained its normal shaped. The serous acinar cells had large irregular euchromatic nuclei. The lateral borders of acinar cell were closely interdigitated. Few cytoplasmic vacuoles were detected. Few short stubby microvilli extended from these cells into the acinus central lumen had been seen Fig. (4B).

Table (1): Statistical comparisons between mean values of the MDA and the GSH in different studied groups using ANOVA (analysis of variance) test.

\begin{tabular}{lll}
\hline Group & $\begin{array}{c}\text { MDA (nmol/g } \\
\text { tissue) } \pm \text { SD }\end{array}$ & $\begin{array}{l}\text { GSH (nmol/g } \\
\text { tissue) } \pm \text { SD }\end{array}$ \\
\hline Control group & $10.25 \pm 0.08 \mathbf{d}$ & $2.41 \pm 0.04 \mathbf{b}$ \\
Vit. C-treated group & $10.75 \pm 0.09 \mathbf{c}$ & $2.47 \pm 0.04 \mathbf{a}$ \\
MTX-treated group & $48.00 \pm 0.71 \mathbf{a}$ & $0.87 \pm 0.02 \mathbf{d}$ \\
MTX-withdrawal group & $31.15 \pm 0.06 \mathbf{b}$ & $1.38 \pm 0.03 \mathbf{c}$ \\
MTX+ Vit. C-treated group & $10.34 \pm 0.31 \mathbf{c d}$ & $2.43 \pm 0.02^{\mathbf{a b}}$ \\
$p$-value & $<0.001 * *$ & $<0.001 * *$ \\
LSD at 0.05 & 0.4631 & 0.039
\end{tabular}

SD: Standard Deviation.

**: Highly significant $(p<0.001) . \mathrm{n}=5 /$ group.

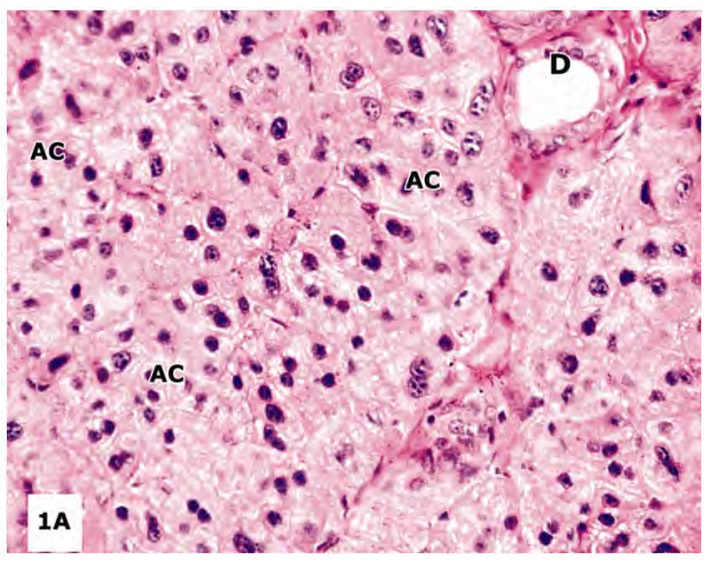

Fig. (1A): A photomicrograph of the control parotid gland section showing the typical parenchyma as the ducts (D) and closely packed purely serous acini (AC). These acini reveal pyramidal-shaped cells with rounded basal vesicular nuclei and central lumens. (H \& E X400).

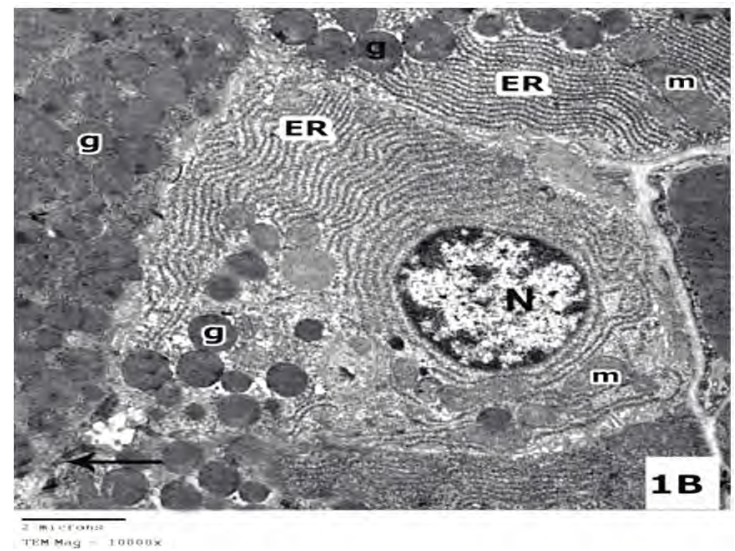

Fig. (1B): An electron micrograph of the control parotid gland showing serous acinar cells. The serous acinar cells have large regular euchromatic nucleus $(\mathrm{N})$, extensive regular parallel cisternae of rough Endoplasmic Reticulum (ER) and few mitochondria (m) are seen. Numerous electron-dense secretory granules $(\mathrm{g})$ are noticed. The lateral borders of acinar cells are closely interdigitated, Junctional complex (arrow) is observed between the two adjacent cells. (TEM 1-B X10000).

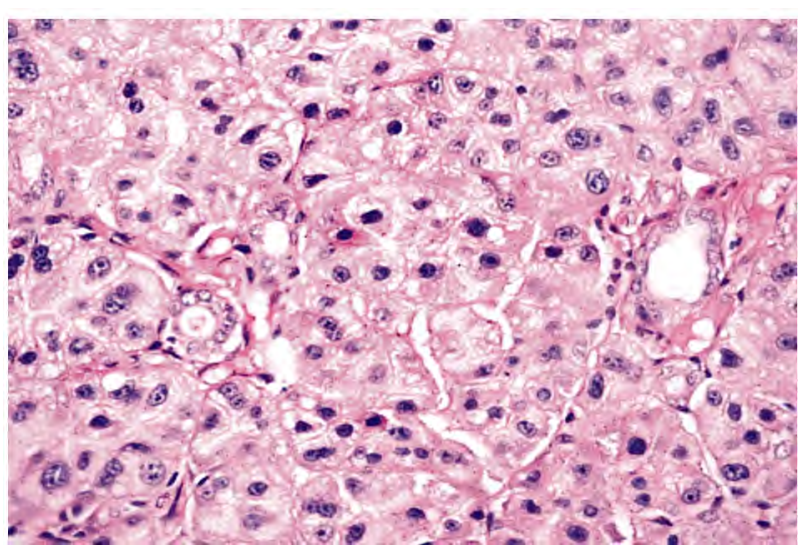

Fig. (1C): Photomicrograph of parotid gland section in the Vit. C-treated group (Group II) showing nearly typical parenchyma as the Ducts (D) and closely packed purely serous acini (AC). These acini reveal pyramidal-shaped cells with rounded basal vesicular nuclei and central lumens. (H \& E X400). 

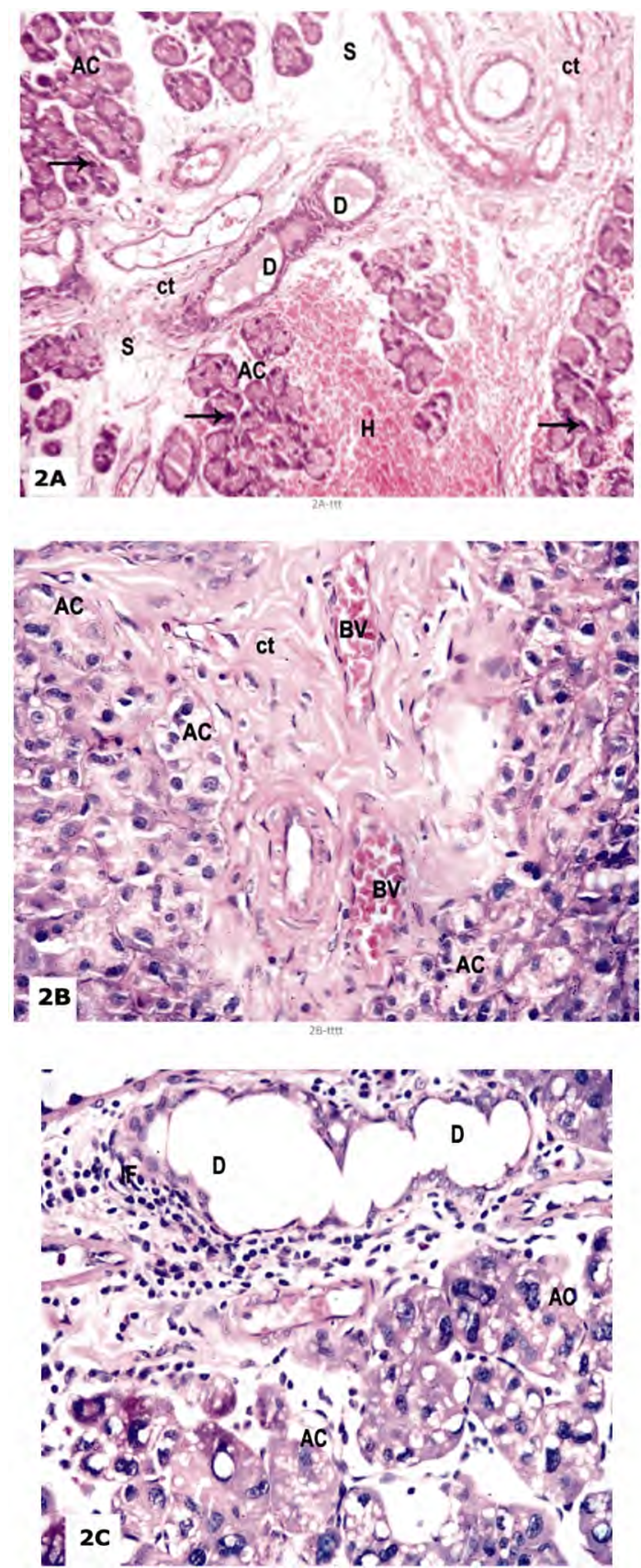

Fig. (2): (A-C): Photomicrographs of parotid gland sections in the MTX-treated group (Group III) showing; (A): Disorganized acini (AC) with disappearance of their lumens. Most nuclei (arrow) of the acinar cells at the peripheral and pyknotic or darkly stained are observed. These acini are widely Separated (S) with connective tissue fibers (ct) and hemorrhage (H). Dilated Ducts (D) with stagnation of secretion are also noticed. (B): Numerous vacuolated Acinar Cells (AC) are seen. Congested blood vessels (BV) and thicking of connective tissue (ct) are noticed. (C): Vacuolated Acinar Cell (AC) and extensively dilated irregular Duct (D) are observed. Notice, preductal cellular Infiltration (IF) are observed. (H \& E A X100; B \& C X400).
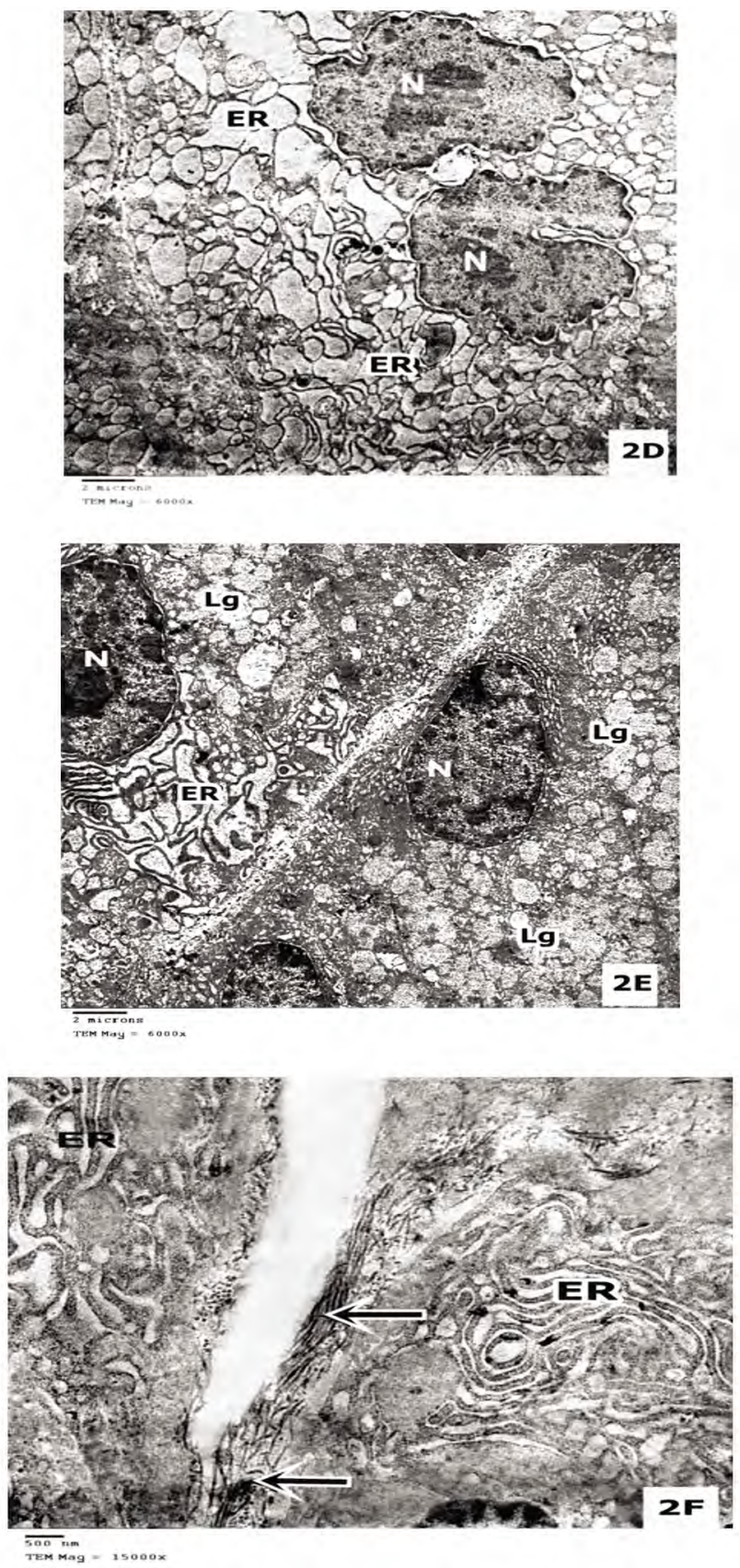

Fig. (2): (D-F): Electron micrographs of the parotid gland from the MTX-treated rats (Group III) showing; D) Acinar cells with irregular or indented nuclei $(\mathrm{N})$ and extensively dilated irregular rough Endoplasmic Reticulum (ER) are seen. (E): Some acinar cells with large numerous electron lucent granules $(\mathrm{Lg})$, extensively dilated irregular Endoplasmic Reticulum (ER) and also irregular heterochromatic Nucleui $(\mathrm{N})$ are seen. $(\mathrm{F})$ : Collagen fibers (arrow) and also irregular arranged Endoplasmic Reticulum (ER) are seen. (TEM 2-D X6000; 2-E X6000 and 2-F X15000). 

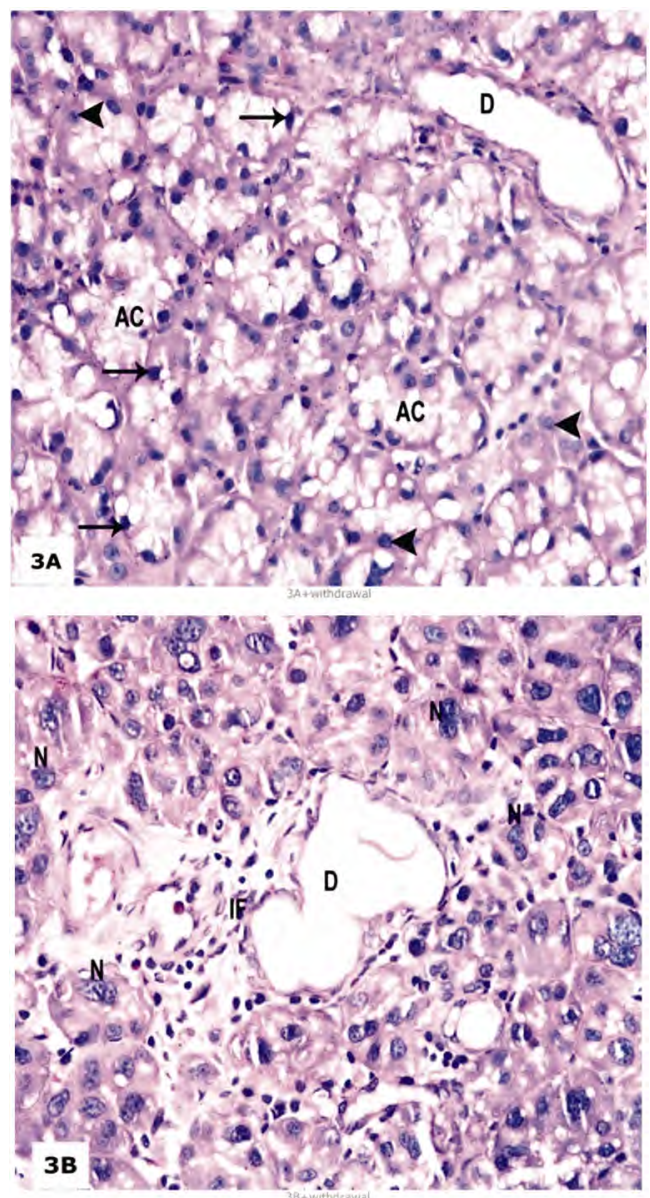

Fig. (3): (A,B): Photomicrographs of parotid gland sections in the MTX-withdrawal group (Group IV) showing; A) Numerous vacuolated Acinar Cells (AC) with darkly stained nuclei (arrow) and also some vesicular nuclei (arrow head). Notice, dilated Ducts (D). (B): Other acini with different form of mitotic form nuclei (N) are demonstrated. Dilated ducts (D) with few inflammatory infiltrated cells (IF) are detected. (H \& E, A \& B X400).

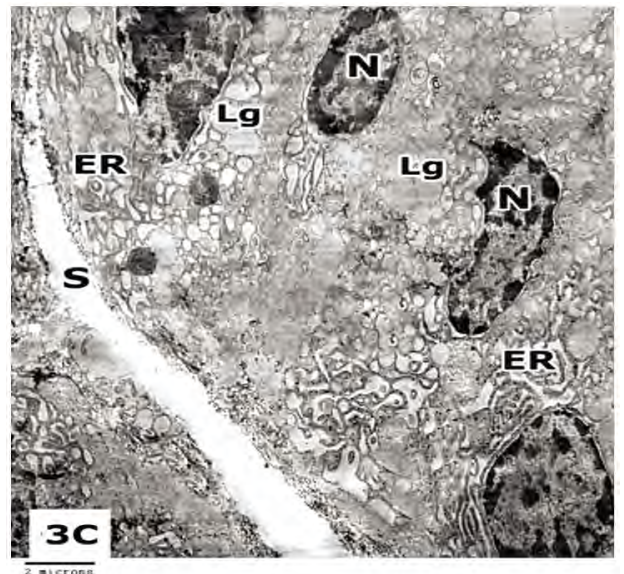

Fig. (3): (C): Electron micrographs of the parotid gland from the MTX-withdrawal rats (Group IV) showing some acinar cells with irregular heterochromatic nuclei $(\mathrm{N})$ and cystic or irregular dilation of endoplasmic reticulum (ER). Small few electron lucent granules $(\mathrm{Lg})$ are demonstrated. Wide separation (S) between acini is also detected. (TEM, 3-C X8000).

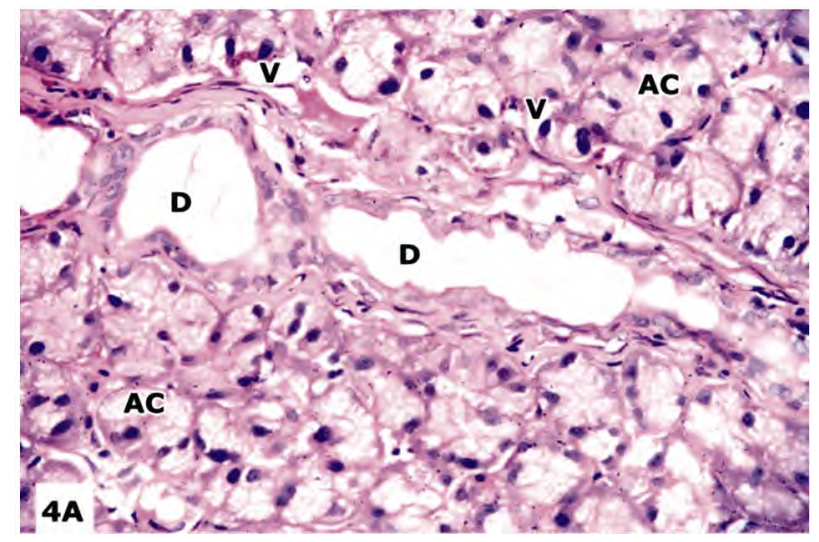

Fig. (4): (A): A photomicrograph of sections in the parotid glands from the MTX + Vit. C-treated group (Group V) showing closely packed purely serous acini (AC). Some Vacuolations (V) are still observed. The Ducts (D) still showing dilation. (H \& E X400).
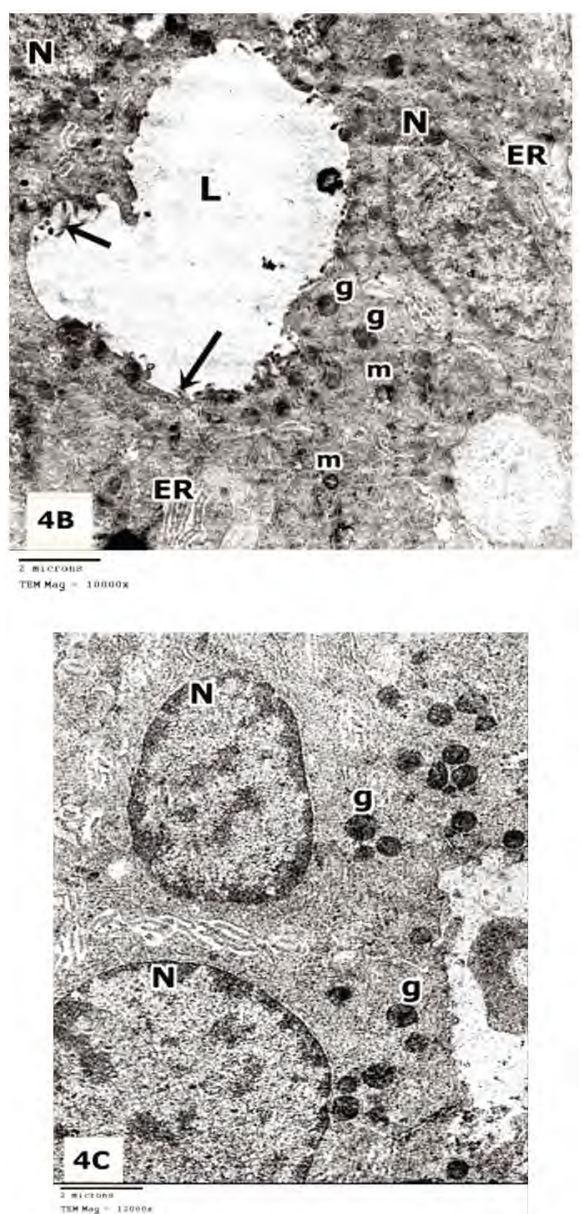

Fig. (4): (B,C): Electron micrographs of the parotid gland from the MTX + Vit. C-treated group (Group V) showing serous acinus with central Lumen (L). The serous acinar cells have large irregular euchromatic Nuclei $(\mathrm{N})$, rough Endoplasmic Reticulum (ER) and few mitochondria (m) are seen. Few short stubby microvilli (arrow) extend from these cells into the lumen and numerous small-sized electron-dense secretory granules (g) are noticed. Notice, lateral borders of these acinar cells are closely interdigitated. (TEM, 4-B X10000 \& 4-C $\mathrm{X} 12000)$ 


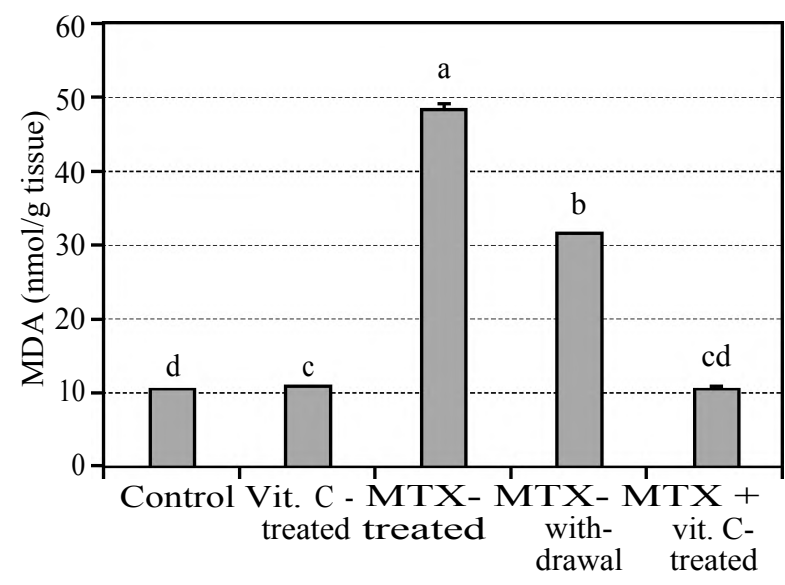

Chart (1): Bar charts showing the changes in the activity of the MDA, in control, Vit. C-treated, MTX-treated, MTXwithdrawal and MTX + Vit C-treated groups. Bars carrying different superscripts (a, b, c and d) are statistically significant differences at $(p \leq 0.05)$, as determined using One-Way ANOVA followed by the Duncan's test, $n=5 /$ group. Values are expressed as the means $\pm \mathrm{SE}$.

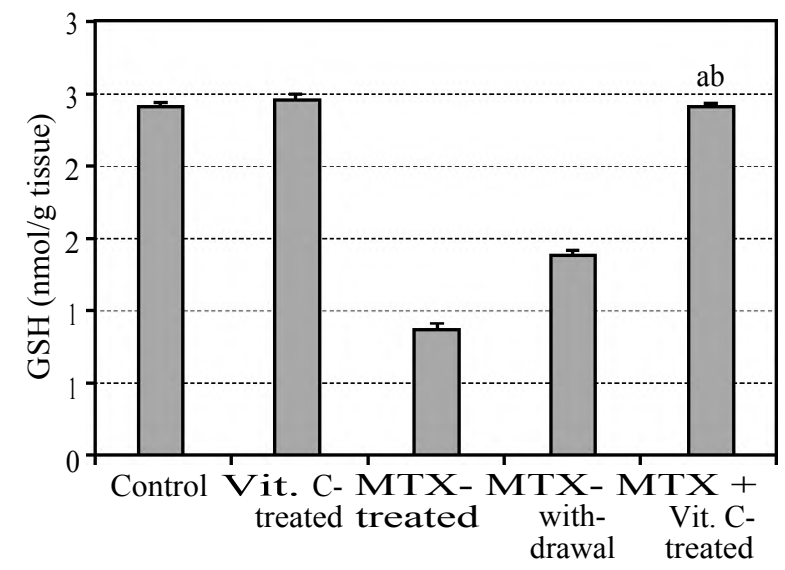

Chart (2): Bar charts showing the changes in the activity of the GSH, in control, Vit. C-treated, MTX-treated, MTXwithdrawal and MTX + Vit C-treated groups. Bars carrying different superscripts (a, b, c and d) are statistically significant differences at $(p \leq 0.05)$, as determined using One-Way ANOVA followed by the Duncan's test, $n=5 /$ group. Values are expressed as the means \pm SE.

\section{Discussion}

MTX is a cytotoxic chemotherapeutic agent used in several types of tumors as breast cancer, lung, leukemia, testicular tumors and other malignancies. It is also recommended in inflammatory related diseases as rheumatoid arthritis and psoriasis. The most common side effects in patients treated with MTX are stomatitis, diarrhea, nausea, vomiting, alopecia, hepatotoxicity and bone marrow depression; these effects are commonly resulted from generation of free radicals and lipid peroxidation [19] .

The parotid gland was chosen as it is the largest major salivary gland that accounts for more than
$50 \%$ of stimulated saliva secretion. Besides, it is less affected by drugs as the time taken for the drug to reach its maximum concentration in parotid's saliva is longer than that in submandibular. Life quality is markedly affected in patients with irreversible loss of salivary gland function $[20,21]$.

In cancer chemotherapy, the mechanism of action of certain antineoplastic agents involves generation of free radicals further leading to cellular damage and malignant cells necrosis. Hence the use of antioxidant during chemotherapy is criticized due to fear of causing interference with the efficacy of the drug. On the contrary, it is proven that using of antioxidant supplements allowing patients to tolerate possibly higher effective doses of chemotherapy, thereby, increasing the chance of better tumor response and improved survival rate. So that, co-administration of antioxidant during chemotherapy has been highly controversial topic. The questions repeatedly put forth are "Do antioxidants increase or decrease the efficacy of anticancer agent? Do antioxidants protect normal tissue and ameliorate toxicity"? [22].

During the course of chemotherapy. It is important to consume anti-oxidant Vitamins like $\mathrm{C}$ and $\mathrm{E}$ (the most important naturally-occurring antioxidant vitamins) for alleviating the oxidative stress generated. The main protective effects of vitamin $\mathrm{C}$ against cancer could be due to its antioxidant effect due to its capacity to lose a hydrogen atom and to form a relatively stable ascorbate free radical [23].

Concerning microscopic examination of the parotid glands sections of the MTX-treated group, it exhibited disorganization of parotid tissues in this study. Most of the serous acini had irregular outlines and were widely separated. Marked hemorrhage in between acinar cells was also noticed. The cytoplasm of the acinar and ductal cells were faintly stained with variable sized vacuoles displacing the nuclei more peripherally. These findings were in consistence with Mahmoud et al., [24] who reported that there was a glandular degeneration determined by marked vacuolations in acinar and ductal cells with complete replacement of some acinar cells by large vacuoles. Such findings might be explained by the accumulation of lipid droplets to be unutilized fatty acids resulted from cellular dysfunction. They added that, these fat droplets might coalesce together forming a large vacuole. Another explanation by Lombaert et al., [25] who explained that vacuolations in both acini and ducts might be due to mitochondrial swelling. 
Şener et al., [26] demonstrated significant increases of collagen fibers in ileum, liver and kidney after MTX exposure. This was supported in our results by glandular degeneration, prominent increase in connective tissues in between acini and around ducts accompanied by a reduction in parenchymal structures in light and ultrathin sections.

This MTX-induced acinar and ductal cell death was assumed to be apoptosis, which was supported in our study by the presence of shrunken dark irregular acinar and ductal nuclei. More reinforcement came from the demonstrated rER dilatation which was considered as cellular changes preceding apoptosis [27].

The duct system dilatation was noticed by light microscopic examination in the MTX-treated group of our study and this was similarly reported in former studies [28,29], and attributed to MTX negative effect on myoepithelial cells embracing the ducts. Moheb et al., [30] added that dilation led to stagnation of secretion and consequently salivary dysfunction, failure of saliva ejection into the mouth and xerostomia.

Marked hemorrhage in between the acinar cells was also noticed in the present study. Other acini showed notable granular degeneration as inflammatory cell infiltration and vascular congestion. These results were supported by Hsu et al., [31] who explained all these findings by the oxidative stress effect of MTX. It was evidenced to reduce intracellular glutathione-based antioxidants and produce oxygen free radicals during its intracellular metabolism. This oxidant/antioxidant imbalance leads to lipid peroxidation followed by organelles and plasma membranes lysis. These inflammatory reactions could aim to transport more blood to the degenerated tissues. Accordingly, inflammatory reactions "such as mononuclear infiltration and the presence of mast cells with dispersed granules within the thickened septa" could be explained in accordance with Moubarak [32].

In the present study, a highly significant increase in the MDA in the MTX-treated group when compared with other groups was noticed. While the GSH showed a highly significant decrease in the same group when compared with other groups. These findings were in consistence with Savran et al., [7] who noticed that MTX markedly altered the oxidative stress parameters, such as SOD, MDA, CAT and GSH-Px levels in the liver and kidney. SOD, GSH-Px and CAT activities were significantly decreased in the only MTX-treated rats when compared with the control group $(p<0.05)$, while, the MDA levels showed significant elevation in the MTX-treated group.

The MTX-withdrawal group showed little degree of improvement compared with MTX-treated group in oxidative stress parameters. While, histological examination of this group still showed signs of parotid degeneration in the form of epithelial vacuolization, inflammatory cell infiltration around ducts and congested blood vessels were present. The parotid gland ultra-thin sections still revealed small heterochromatic nuclei and cystic dilation of endoplasmic reticulum. Our results were in consistence with those of Tousson et al., [19] who revealed that liver and kidney sections in MTX self-healing group still showed a marked disturbance of organ architecture with strong marked vacuolation when compared with the group treated with antioxidant drug as L-Carnitine.

In the current work, the light micro-scopic and ultra-structu rally examination of the parotid tissue of rats treated with MTX + Vit C revealed improvement as compared to the MTX-treated group. These results were in agreement with that of Savran et al., [7] who reported that the rats which received MTX + Vit. C showed a decrease in the severity of histopathological changes in the renal tissue as compared to the control group.

The results of the present study were also consistent with Antunes et al., [33] who reported that Vit. C showed antioxidant activity and inhibitory effect on the chain reactions of the cisplatingenerated free radicals before they reached the cell targets damaging the glomerular kidney functions. Furthermore, Sayilmaz et al., [34] also reported that the administration of Vit. C before MTX injection decreased a number of apoptotic cells in the testicular tissue so improving the histological manifestations.

In the current study; there were a significant reduction in the MDA and a significant elevation in the GSH levels in the MTX + Vit. C-treated group when compared to the MTX-treated group and the MTX-withdrawal group. Sayilmaz et al., [34] also stated the antioxidant effect of Vit. C which was proved by a significant reduction of the malondialdehyde (MDA) level. Muralikrishnan et al., [35] reported that the antioxidant parameters, such as SOD, CAT, and GSH-PX restored their normal levels after Vit $\mathrm{C}$ treatment in 60 postmenopausal breast cancer patients receiving tamoxifen. 


\section{Conclusion:}

Vit. C has an antioxidant effect against MTXinduced cytotoxicity in the parotid salivary glands of rats. Therefore, it can be used as a protective natural product to the salivary glands in individuals undergoing cancer therapy.

\section{Acknowledgements:}

The authors thank Dr. Assmaa Othman, Professor of Histology, Zagazig University for her great support and scientific experience in this work.

Conflicting interests: The author (s) declared no potential conflicts of interest with respect to theauthorship, research, and/or publication of this article.

Funding: No financial support for the research, authorship and/or publication of this article was received by the author(s).

\section{References}

1- KLARESKOG L., VANDER HEIJDE D., DE JAG ER J.P., GOUGH A., KALDEN J. and SANDA M.: Therapeutic effects of the combination of etanerceept and methotrexate compared with each treatment alone in patients with rheumatoid arthritis: Double blind randomized controlled trial. Lancet, 363: 675-81, 2004.

2- JAHOVIC N., SENER G., CEVIK H., ERSOY Y., ARBAK S. and YEGEN B.C.: Amelioration of methotrexateinduced enteritis by melatonin in rats. Cell Biochem \& Funct, 22: 169-78, 2004.

3- OHRN K.E., SJÖDÉN P.O., WAHLIN Y.B. and ELF M.: Oral health and quality of life among patients with head and neck cancer or haematological malignancies. Support Care Cancer, 9: 528-38, 2001.

4- SONIS S.T.: Oral mucositis in cancer therapy. J. Support Oncol., 2: 3-8, 2004.

5- OZEL O., AYCICEK A., KENAR F., AKTEPE F., SARGIN R., YILMAZ M.D. and DEREKOY F.S.: Histopathologic changes in the rabbit submandibular gland after 5-fluorouracil chemotherapy. Turk. J. Med. Sci., 40: 213-20, 2010.

6- OMAR A.I., YOUSRY M.M. and FARAG E.A.: Therapeutic mechanisms of granulocyte-colony stimulating factor in methotrexate-induced parotid lesion in adult rats and possible role of telocytes: A histological study. Egyptian Journal of Histology, 41 (1): 93-107, 2018.

7- SAVRAN M., CICEK E., DOGUC D. K., ASCI H., YESILOT S., CANDAN I.A. and OZER M.K.: Vitamin C attenuates methotrexate-induced oxidative stress in kidney and liver of rats. Physiology International, 104 (2): 13949, 2017.

8- HARRISON F.E., MEREDITH M.E., DAWES S.M., SASKOWSKI J.L. and MAY J.M.: Low ascorbic acid and increased oxidative stress in gulo_/_ mice during development. Brain Res., 1349: 143-52, 2010.

9- DERAZ E.M., ABD-ELHAMID A.M. and FAHMI A.N.: Histological and ultrastructural study of the effect of potassium dichromate with evaluation of potential protective role of Vitamin $\mathrm{C}$ on submandibular salivary gland of rats. J. Am. Sci., 12 (2): 84-90, 2016.

10- PRADHAN R., KOIRALA S., ADHIKARI N., SANNITHI N., THAKUR A., ADHIKARI B., REDDY Y.P. and ANDKOIRALA U.: Protection against Methotrexate Induced Hepato-Renal Toxicity in Rats by Zinc and its Combination with Vitamin C and Vitamin E. Med. Safe. Glo. Heal., 5: 127, 2016.

11- YUKSEL Y., YUKSEL R., YAGMURCA M., HALTAS H., ERDAMAR H., TOKTAS M. and OZCAN O.: Effects of quercetin on methotrexate-induced nephrotoxicity in rats. Human \& experimental toxicology, 36 (1): 51-61, 2017.

12- IACUC: Inistitutional Animal Care and Use Committe. Available at: https://research.iu.edu/doc/compliance/ animal-care/iupui/iupui-iacuc-use-of-non-pharmaceuticalgrade-chemicals-compounds.pdf, 2014.

13- PLACER Z.A., CUSHMAN, L.L., and JOHNSON B.C.: Estimation of product of lipid peroxidation (MalonylDialdehyde) in biochemical systems. Anal. Biochem., 16: 359-64, 1966.

14- MARAL J., PUGET K. and MICHELSON A.M.: Comparative study of superoxide dismutase, catalase and glutathione peroxidase levels in erythrocytes of different animals. Biochem. Biophys. Res. Commun., 4: 1525-35, 1977.

15- KIERNAN J.: Histological and histochemical methods: Theory and practice. ed. Arnold publisher. London, New York \& New Delhi. pp. 111-62, 2001.

16- HAYAT M.A.: Chemical fixation. In: Principles and techniques of electron microscopy: Biological applications. 4 th ed. Edinburg, UK: Cambridge University Press. pp. 4-85, 2000.

17- DYKSTRA M.J. and REUSS L.E.: Staining methods for semithins and ultra thins. In: Biological electron microscopy, theory, techniques and troubleshooting. 2 nd ed. Kluwer Academic Publishers/Plenum Publishers. pp. 17596, 2003.

18- EMSLEY R., DUNN G. and WHITE I.R.: Mediation and moderation of treatment effects in randomised controlled trials of complex interventions. Stat. Methods Med. Res. 19: 237-70, 2010.

19- TOUSSON E., ATTEYA Z., EL-ATRASH A. and JEWEELY O.I.: Abrogation by Ginkgo Byloba Leaf Extract on Hepatic and Renal Toxicity Induced by Methotrexate in Rats. Journal of Cancer Research and Treatment, 2 (3): 44-51, 2014.

20- HUMPHREY S.P. and WILLIAMSON R.T.: A review of saliva: Normal composition, flow, and function. J. Prosthet. Dent., 85: 162-9, 2001.

21- JENSEN S.B., PEDERSEN A.M., REIBEL J. and NAUNTOFTE B.: Xerostomia and hypofunction of salivary glands in cancer therapy. Support Care Cancer, 11: 20725, 2003.

22- SINGH K., BOHRI M., KASU Y.A., BHAT G. and MARAR T.: Antioxidants as precision weapons in war against cancer chemotherapy-induced toxicity-Exploring the armoury of obscurity. Saudi Pharma J., 26: 177-90, 2018. 
23- SUHAIL N., BILAL N., KHAN H.Y., HASAN S., SHARMA S., KHAN F., MANSOOR T. and BANU N.: Effect of vitamins $\mathrm{C}$ and $\mathrm{E}$ on antioxidant status of breast-cancer patients undergoing chemotherapy. Journal of Clinical Pharmacy and Therapeutics, 37: 22-6, 2012.

24- MAHMOUD E.F., MAHMOUD M.F. and ABD AL HALEEM M.: Royal Jelly ameliorates oxidative stress and tissue injury in submandibular salivary gland of methotrexate treated rabbits: Immunohistochemical study. J. Am. Sci., 8: 501-8, 2012.

25- LOMBAERT I.M., BRUNSTING J.F., WIERENGA P.K., KAMPINGA H.H., DE HAAN G. and COPPES R.P.: Cytokine treatment improves parenchymal and vascular damage of salivary glands after irradiation. Clin. Cancer Res., 14: 7741-50, 2008.

26- ȘENER G., EKŞIOGLU-DEMIRALP E., ÇETINER M., ERCAN F. and YEGEN B.Ç.: B-glucan ameliorates methotrexate-induced oxidative organ injury via its antioxidant and immunomodulatory effects. European Journal of Pharmacology, 542 (1-3): 170-8, 47, 2006.

27- TAKAHASHI S., NAKAMURA S., DOMON T., YAMAMOTO T. and WAKITA M.: Active participation of apoptosis and mitosis in sublingual gland regeneration of the rat following release from duct ligation. J. Mol. Histol., 36: 199-205, 2005.

28- EL-AGAMY A.A., AFIFI O.K. and SHETA A.A.: Protective Role of PanaxGensing on Fluvoxamine Maleate Induced Structural Changes in the Submandibular Salivary Gland of Rats. Nat. Sci., 12: 21-9, 2014.

29- AL-REFAI A.S., KHALEEL A.K. and ALI S.: The Effect of Green Tea Extract on Submandibular Salivary Gland of Methotrexate Treated Albino Rats: Immunohistochemical Study. J. Cytol. Histol., 5: 6 pages, 2014.

30- MOHEB M., EL-SAKHAWY M.A., SHERIF H. and SHREDAH M.: Histological evaluation of the effect of nutmeg on parotid salivary glands of adult male albino rats. Life Sci. J., 11: 1063-8, 2014.

31- HSU P.C., HOUR T.C., LIAO Y.F., HUN Y.C., CHANG W.H., KAO M.C., TSAY G.J., HUNG H.C. and LIU G.Y.: Increasing ornithine decarboxylase activity is another way of prolactin preventing methotrexate-induced apoptosis: Crosstalk between ODC and BCL-2. Apoptosis, 11: 389-99, 2006

32- MOUBARAK R.: The effect of hypercholesterolemia on the rat parotid salivary gland (histopathological and immunohistochemical study). Cairo Dental Journal, 24: 19-28, 2008.

33- ANTUNES L.M.G., DARIN J.D.A.C. and BIANCHI M. D.L.P.: Protective effects of Vitamin C against cisplatininduced nephrotoxicity and lipid peroxidation in adult rats: A dose-dependent study. Pharmacological Research, 41 (4): 405-11, 2000.

34- SAYILMAZ A., KARABULUT Y.Y. and ÖZGÖRGÜLÜ A.: The histopathological evaluation of healing effects of Vitamin C administered before methotrexate therapy on testicular injury induced by methotrexate. Turkish Journal of Urology, 42 (4): 235, 2016.

35- MURALIKRISHNAN G., AMANULLAH S., BASHA M.I., BOOPALAN S., VIJAYAKUMAR S. and SHAKEEL F.: Effect of Vitamin $C$ on lipidperoxidation and antioxidant status in tamoxifen-treated breast cancer patients. Chemotherapy, 56: 298-302, 2010. 


\section{تغيرات الإجهاد التأكسلى الناجمة عن عقار الميثوتريكسان

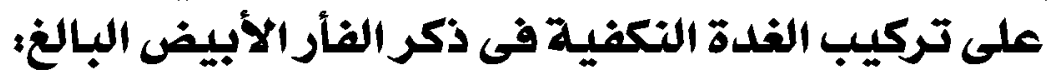

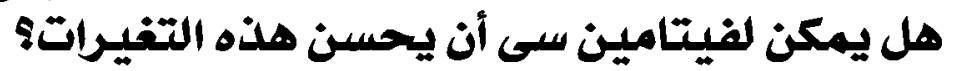

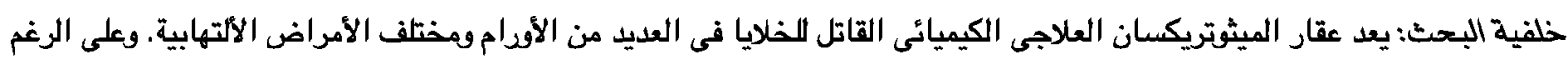

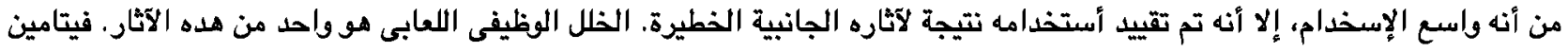

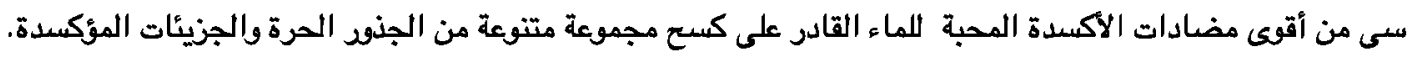

الهدف من العمل: العمل للكثف عن الدود الممكن لفيتامين سى كمضاد للاكسيدة على التغيرات الناتجة من عقار الميثوتريكسان على تركيب

الهادة والطرق الهستخدمة: تم تقسيم خمسين من ذكود الفئران البيضاء البالغة إلى خمس مجموعات، المجموعة الأولى: تناولت غذاء

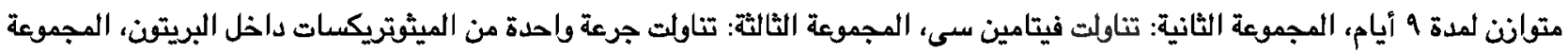

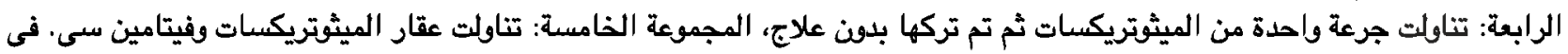

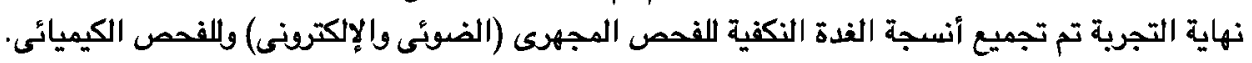

النتائج: سبب عقار الميثوتريكسات تفيرات هيستوباثولوجية وتركيه على الغدة النكفية. أظهرت المجموعة المعالجة بالميثوتريكسات فقدان

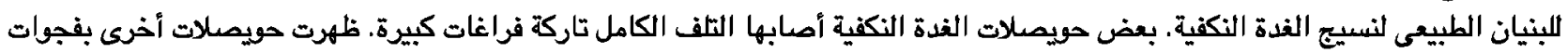

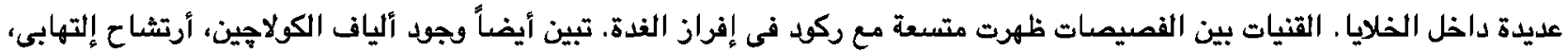

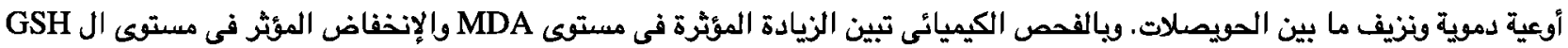

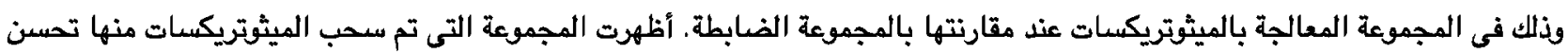

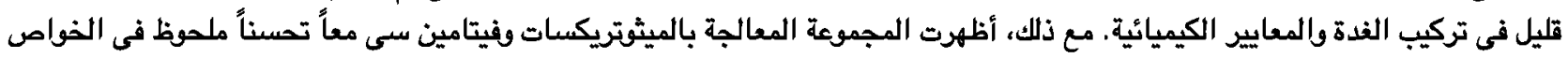

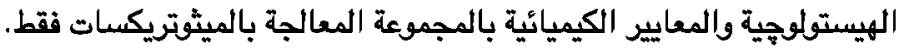

الخلاصدة: أتضع من نتائج هذه الدراسة يحدث عقار الميثوتريكسات تغيرات مدمرة ملحوظة فى تركيب الغدة النكفية وفيتامين سي كعامل قوى مضاد للاكسدة يعمل على تخفيف إصابة الغدة النكفية. 